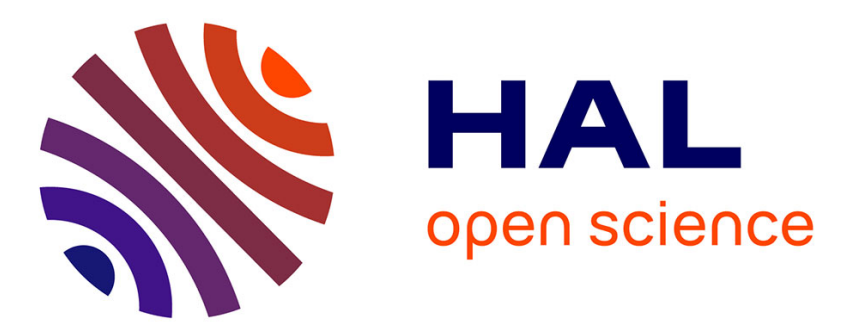

\title{
Applicability of the resistance integration method on bonded fasteners loaded in tension in uncracked concrete under ISO 834-1 fire
}

Omar Al-Mansouri, Romain Mège, Nicolas Pinoteau, Thierry Guillet, Sébastien Rémond

\section{To cite this version:}

Omar Al-Mansouri, Romain Mège, Nicolas Pinoteau, Thierry Guillet, Sébastien Rémond. Applicability of the resistance integration method on bonded fasteners loaded in tension in uncracked concrete under ISO 834-1 fire. 11th International Conference on Structures in Fire (SiF2020), Nov 2020, Brisbane, Australia. 10.14264/b469116 . hal-03508731

\section{HAL Id: hal-03508731 \\ https://hal.science/hal-03508731}

Submitted on 3 Jan 2022

HAL is a multi-disciplinary open access archive for the deposit and dissemination of scientific research documents, whether they are published or not. The documents may come from teaching and research institutions in France or abroad, or from public or private research centers.
L'archive ouverte pluridisciplinaire HAL, est destinée au dépôt et à la diffusion de documents scientifiques de niveau recherche, publiés ou non, émanant des établissements d'enseignement et de recherche français ou étrangers, des laboratoires publics ou privés. 


\section{Proceedings of the 11th International Conference on Structures in Fire}

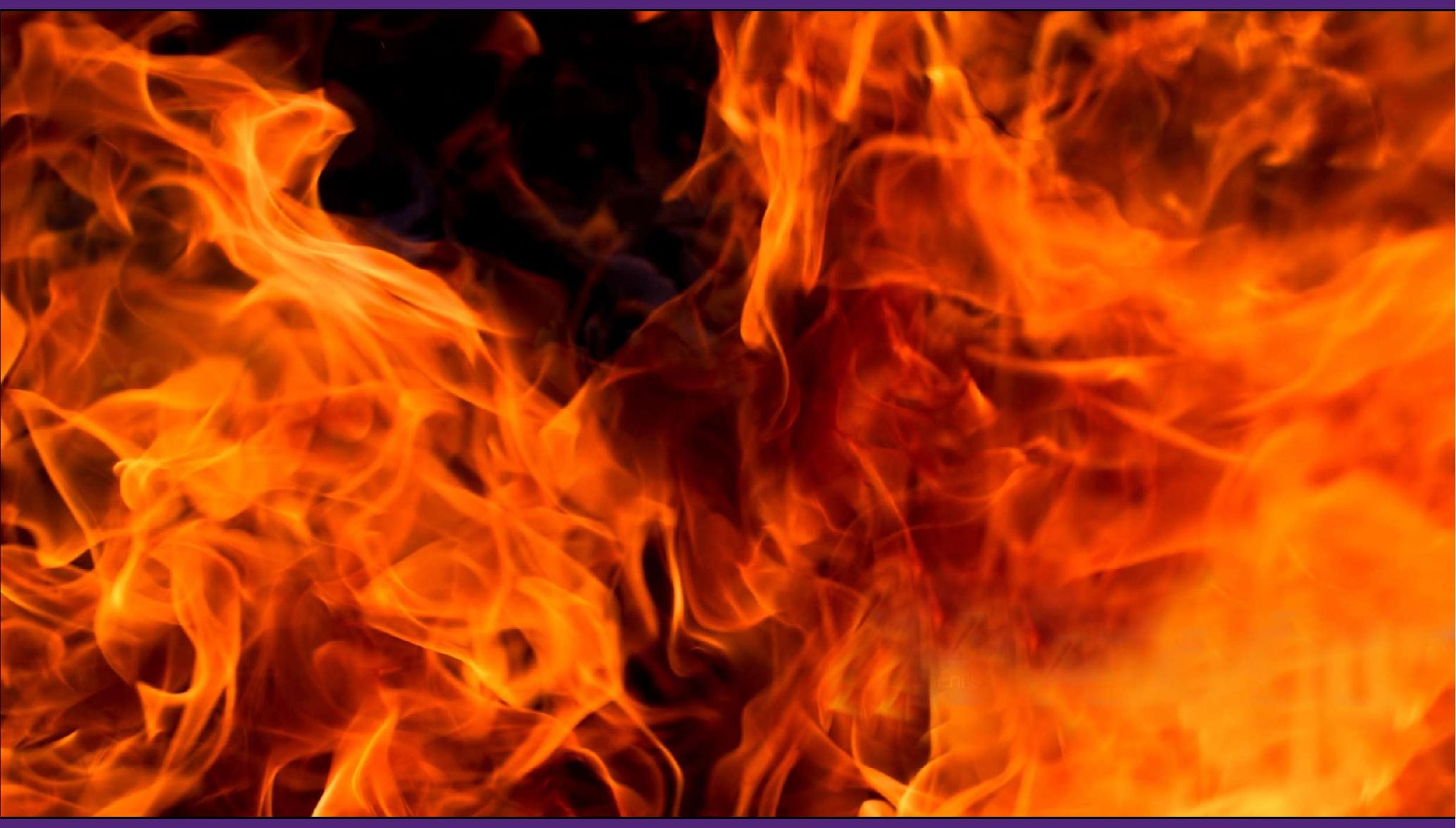

Editors: David Lange, Cristian Maluk, Kang Hai Tan, Dong Zhang, Yao Zhang, Julian Mendez Alvarez, Juan Hidalgo, Felix Wiesner, Martyn Mclaggan, Abdulrahman Zaben, Wenxuan Wu, Hangyu Xu

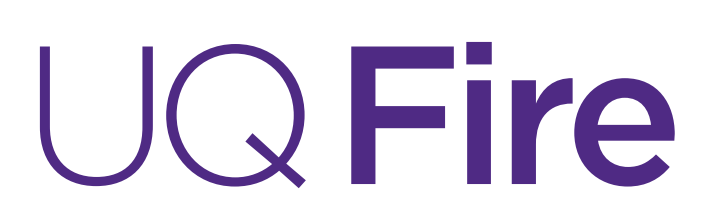




\title{
APPLICABILITY OF THE RESISTANCE INTEGRATION METHOD ON BONDED FASTENERS LOADED IN TENSION IN UNCRACKED CONCRETE UNDER ISO 834-1 FIRE
}

\author{
Omar Al-Mansouri ${ }^{1}$, Romain Mège ${ }^{2}$, Nicolas Pinoteau ${ }^{3}$, Thierry Guillet ${ }^{4}$, Sébastien Rémond ${ }^{5}$
}

\begin{abstract}
European guidelines for fire design of post-installed anchor systems are limited to mechanical (e.g., expansive, undercut) mechanisms of load transfer and the steel failure mode, whereas the adhesive bond mechanism remains unaccounted for in bonded anchors. Furthermore, current design methods are not based on temperature profiles but rather give a specific resistance for a certain fire duration. This paper presents a study of the applicability of the Resistance Integration Method, proposed originally for Post-Installed Reinforcement (PIR) by Pinoteau, on bonded anchors. This method is validated from comparison of test results obtained from a research project conducted at CSTB on bonded anchors under fire, and calculation. The collected data include tests conducted on anchor sizes of M8 and M12 using epoxy adhesive. Design using Pinoteau's method can be tricky depending on the entry data (numerical calculation of temperature profiles and bond stress vs. temperature relationship adopted in the integration process) and may yield different results (sometimes too conservative) if the wrong parameters are adopted. This paper also presents a study on the influence of these parameters on the outcome of the method. Finally, recommendations are given to ensure good design values for bonded anchors under fire based on the assessment at high temperatures.
\end{abstract}

Keywords: adhesive resin, bonded anchor, fire tests, thermal distribution, numerical model

\footnotetext{
${ }^{1} \mathrm{PhD}$ candidate, Centre Scientifique et Technique du Bâtiment (CSTB), 84 avenue Jean Jaurès, Champs-sur-Marne, 77447 Marne-la-Vallée Cedex 2, France

IMT Lille-Douai, Univ. Lille, EA 4515 - LGCgE, Département Génie Civil \& Environnemental, F-59000 Lille, France e-mail: Omar.ALMANSOURI@cstb.fr

${ }^{2}$ Head of division (Dr. Eng.), Centre Scientifique et Technique du Bâtiment (CSTB), 84 avenue Jean Jaurès, Champs-sur-Marne, 77447 Marnela-Vallée Cedex 2, France

e-mail: Romain.MEGE@ cstb.fr

${ }^{3}$ Research Engineer (Dr. Eng.), Centre Scientifique et Technique du Bâtiment (CSTB), 84 avenue Jean Jaurès, Champs-sur-Marne, 77447 Marne-la-Vallêe Cedex 2, France

e-mail: Nicolas.PINOTEAU@cstb.fr

${ }^{4}$ Expert in fixings (Senior Eng.), Centre Scientifique et Technique du Bâtiment (CSTB), 84 avenue Jean Jaurès, Champs-sur-Marne, 77447 Marne-la-Vallée Cedex 2, France

e-mail: Thierry.GUILLET@ @stb.fr

${ }^{5}$ Professor, Univ Orléans, Univ Tours, INSA CVL, LaMé, EA 7494, France

e-mail: Sebastien.REMOND@ univ-orleans.fr
} 


\section{INTRODUCTION}

Post-installed bonded anchors are commonly used for steel to concrete connections and offer a great flexibility for construction and renovation projects thanks to their ease of installation and advantageous strength compared to classic cast-in place inserts. Bonded anchors transfer their load to concrete through bond and friction. Bonded anchors can be designed to ensure similar strengths to post-installed mechanical anchors at ambient temperature. However, they are sensitive to several environmental factors [1 -4$]$. Indeed, the assessment of bonded anchors in European [5] and American guidelines [6] require tests on different anchor geometries in dry and wet concrete, minimum curing time, freeze/thaw conditions, high alkalinity, sulphurous atmosphere, installation in insufficiently clean holes, installation in freezing conditions, short and long-term temperatures...etc. Several accidents around the world happened due to the insufficient knowledge or of the behavior or poor design choices of bonded anchors at high temperatures. The collapse of the Big Dig Tunnel in the USA (2006) [7], the bridge fencing collapse in Atlanta [8] and the Sasago tunnel in Japan (2012) occurred because of the poor choice of adhesive, inadequate installation and increase of temperature inside the tunnels. The mechanical properties of adhesive resins are particularly temperature dependent [9]. Therefore, assessment and design criteria of bonded anchors in fire situations should be provided.

So far, assessment and design guidelines do not offer evaluation and design methods for bonded anchors under fire. Post-Installed Rebars however, have an existing guidelines allowing to assess the bond stress vs. temperature curve of a PIR connection at high temperature [10]. This curve is obtained by a minimum of 20 tests on a $12 \mathrm{~mm}$ rebar. The anchor (PIR) is installed in a steel coated cylinder with $10 * \mathrm{~d}$ embedment depth. After curing of the adhesive, the test is conducted under constant load and increased temperature by electrical heating on the lateral sides of the cylinder. The obtained curve allows to design PIRs under fire using Pinoteau's method (Bond Strength Resistance Integration). The term "resistance" refers to the maximum bond stress obtained locally at the steel/adhesive interface. The load-bearing capacity of the anchor is calculated based on temperature profiles along the embedment depth. In order to determine the resistance profiles, two types of entry data are required. First, the thermal distribution along the embedment depth of the anchor at every time during heating (by numerical calculations). Secondly, a relationship between resistance and temperature is determined by pull-out tests.

Bonded anchors may fail in different failure modes under tensile loading (concrete cone failure, steel failure, pull-out failure of the anchor, splitting failure of concrete and combined concrete cone/pull-out failure) [11 - 12]. Under fire, research studies [13 - 14] have shown that pull-out failure occurs more frequently than other failure modes for common ranges of bonded anchor diameter and embedment.

The steps of resistance integration were established first by Pinoteau et al. [15] and validated on a large scale test at the fire resistance laboratory at CSTB on cantilever-wall connection using PIRs under ISO 8431 fire [16]. Another large scale validation was also performed at CSTB on a slab-wall connection under ISO 843-1 fire by Lahouar et al [17]. Lahouar et al. [18] also proposed a non-linear shear-lag model taking into account the displacement compatibility of PIRs at high temperatures (unaccounted for in resistance integration). Both approaches yielded accurate predictions of fire resistance durations of cantilever connections. Reichert and Thiele [19] also attempted to adapt the method for bonded anchors under fire using axisymmetric thermal modelling of the anchors, but yielding too conservative design values compared to fire tests (i.e. for some configurations, the calculated design value was zero where the anchor was still resisting in the fire test). Lakhani and Hofmann [14,20] presented resistance integration results based on 2D thermal modelling of anchors yielding sometimes higher design values than fire tests (e.g. bonded anchors with insulated fixtures). Al-Mansouri et al. [21] validated this method for the design of bonded anchors. They investigated the parameters influencing fire tests on bonded anchors (fixtures, insulation, concrete member thickness...). The case of an anchor directly exposed to fire (with metallic fixture and without insulating material) was identified as the worst case scenario for which the anchor should be assessed [22]. Al-Mansouri et al. based the resistance integration method on 3D thermal modelling and the example of M12 rods with $110 \mathrm{~mm}$ embedment depth yielding conservative design values compared to fire tests. 
In the framework of the research project (bonded anchors under fire) at CSTB, fire tests were conducted on bonded anchors in uncracked concrete using an epoxy adhesive on two sizes M8 and M12. The testing campaign was performed according to the general requirements of fire tests in [23]. This standard gives a heating curve to be applied inside the furnace (i.e. measured temperature of hot gas inside the furnace during heating). This curve is obtained from the ISO 834-1 standard [16].

The objectives of this paper is to evaluate the calculation method (based on 3D transient heat transfer and Eurocode material properties for steel $[24]$ and concrete $[25,26])$ to test its sensitivity to the entry data (i.e. bond stress vs. temperature relationship adopted in the integration process). The aim is to extend the validity of Pinoteau's method for the design of bonded anchors under fire, and propose recommendations for the evaluation method in consistence with design requirements. Indeed, one of the main entry data for resistance integration method is the bond stress vs. temperature relationship obtained from confined tension tests on bonded anchors at high temperatures according to the guideline for PIRs. The bond stress vs. temperature curve is stopped at a maximum temperature (approximately $300^{\circ} \mathrm{C}$ for a maximum test duration of 3 hours). Unlike PIRs, bonded anchors are not protected by a concrete cover and are directly exposed to fire and exceed $300^{\circ} \mathrm{C}$ along the embedment depth very rapidly in fire situations. The evaluation method is therefore assessed in this paper for bond stress vs. temperature curves extended above this temperature. The extension of the curve should however be limited to another temperature. A new temperature limit is proposed based on the calculations presented in this paper.

\section{DESCRIPTION OF TESTING CAMPAIGNS AND PROPERTIES OF USED MATERIALS}

This section describes the configuration of fire tests on bonded anchors adopted by the fire resistance laboratory at CSTB. Also, the properties of used materials are presented.

\subsection{Description of fire tests}

Fire tests were conducted at CSTB according to the specifications of EOTA TR 020 [27]. Bonded anchors were installed according to manufacturers' instructions and loaded in tension (constant load) before the fire. The fire scenario applied in the furnace on test specimens was ISO 834-1 [16]. After a certain fire exposure time, due to the degradation of material properties of the bond, the constant load could not be supported by the anchors and pull-out failure occurred. Finally, a fire resistance in terms of load and tile are reported for the failed anchor.

Fire test conditions of anchors at CSTB consisted of loading the anchors (installed in beams) using a metallic frame connected to the fixture of the anchor inside the furnace and to a hydraulic jack outside the furnace (Figure 1).
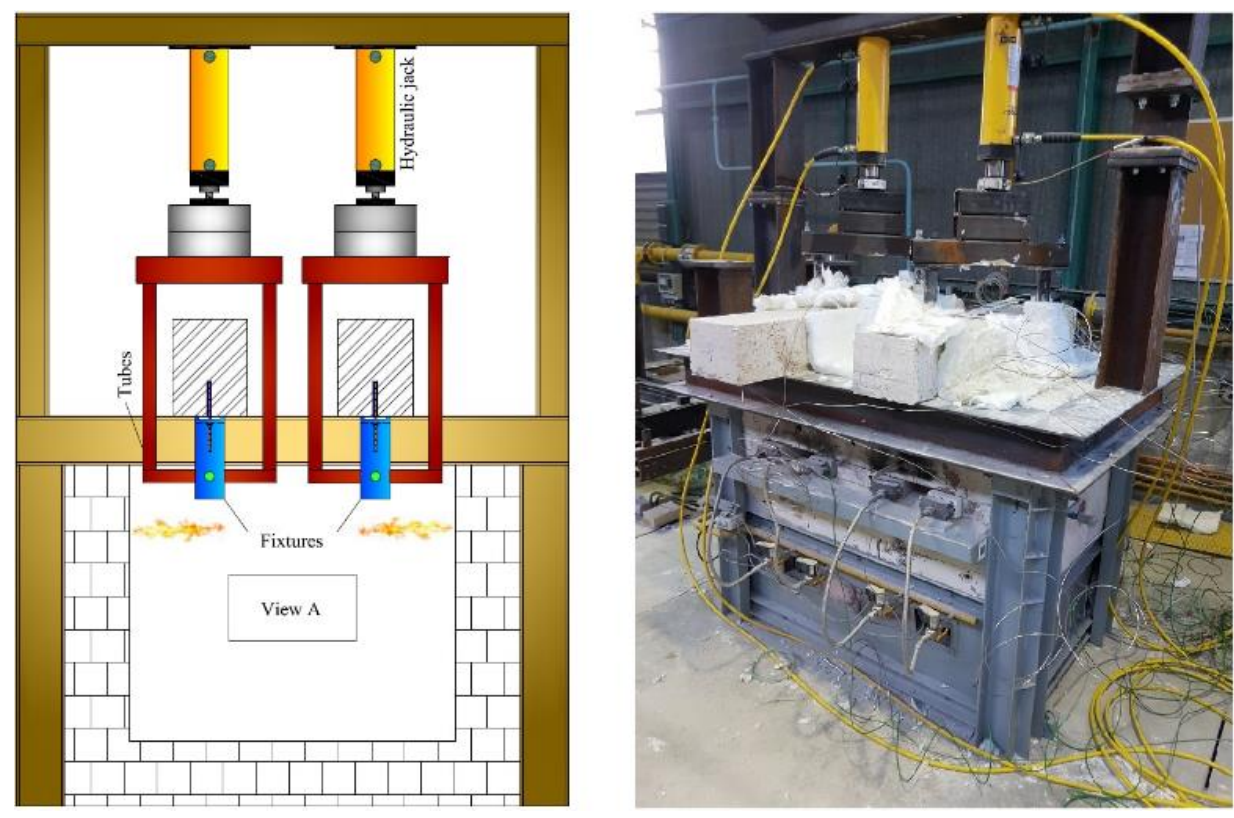
Figure 1: CSTB's furnace and loading system for fire tests on bonded anchors

In a previous experimental work [22] the current authors investigated the influence of the loading system on temperature profiles and resulting load-bearing capacity of bonded anchors and found it negligible. Details of used fixtures were adopted from EOTA TR 020 [27] depending on the applied load of the anchor.

\subsection{Prediction of the load-bearing capacity using the Resistance Integration Method and 3D thermal modelling of the anchor}

The numerical model presented in this paper observes the following characteristics

1. The bonded anchor resin is not modeled.

2. Steel threads are not modeled.

3. The concrete remains uncracked.

4. Concrete spalling is ignored.

5. The fire exposed surface of all elements is subjected to convective and radiative fluxes of ISO 834-1 fire temperatures on all sides.

6. The unexposed fire surface of concrete beams is subjected to convective and radiative fluxes of ambient air at $20^{\circ} \mathrm{C}$.

7. Slip of anchors is ignored.

During a fire, heat transfer occurs between fire and exposed elements at the boundaries via convection and radiation. The heat propagates inside the members via conduction. ANSYS solves the governing differential equation for 3D transient heat conduction using implicit scheme and iterative solver (equation (1)).

$$
\rho c \frac{\partial T}{\partial t}=k\left(\frac{\partial^{2} T}{\partial x^{2}}+\frac{\partial^{2} T}{\partial y^{2}}+\frac{\partial^{2} T}{\partial z^{2}}\right)
$$

By knowing the thermal distribution along the anchor at each moment of heating, it is possible to associate a resistance to each temperature using the resistance-temperature relationship. Hence, the resistance profiles are determined at every moment of fire exposure.

\subsection{Bond stress capacity vs. temperature relationship}

The bond stress capacity vs. temperature relationship was obtained from tests according to EAD 33008700-0601 [10]. Figure 2 shows test results for the epoxy adhesive used in this study. It should be noted that the evaluation curve has a large gap between test 150 and $200^{\circ} \mathrm{C}$. This gap does not respect the maximum distance between neighbouring points in the guidelines of EAD $330087\left(50^{\circ} \mathrm{C}\right)$. However, the other criteria for maximum distance of $1 \mathrm{~N} / \mathrm{mm}^{2}$ is respected. The curves were therefore considered beyond this gap for better representability of the adhesive's behaviour at high temperature. Indeed, adding an additional point would fill the gap and have a negligible statistical weight on the fitting curve.

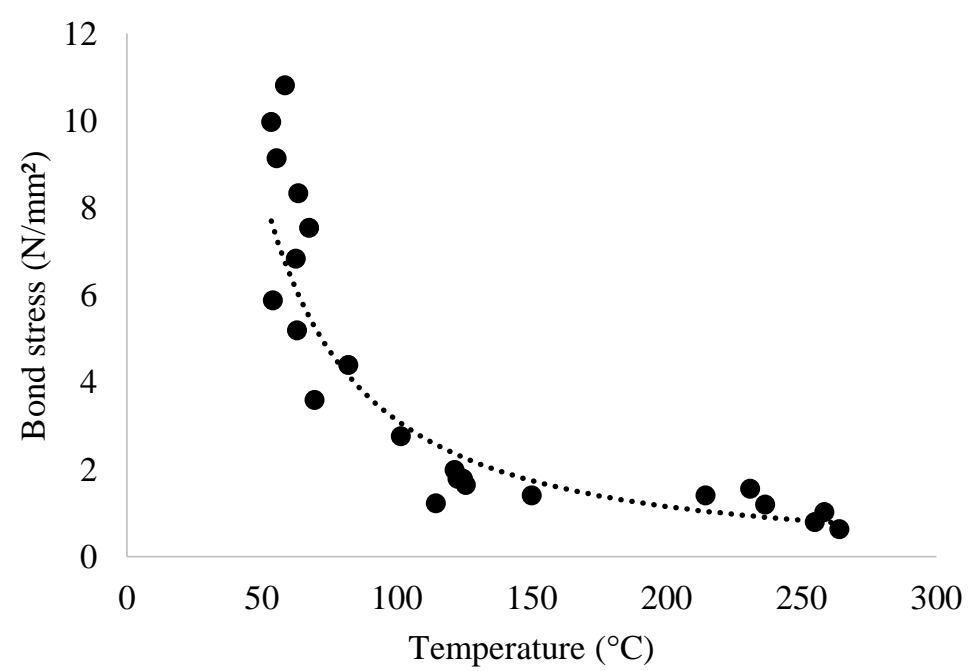

Figure 2: Bond stress vs. temperature relationship for Adhesive-3 according to EAD 330087-00-0601 


\section{VALIDATION OF PINOTEAU'S METHOD FOR FIRE DESIGN OF BONDED ANCHORS}

To investigate the validity of Pinoteau's method, pull-out fire tests were selected from two projects (Table 1). Fig. 3 show a comparison between fire tests and the outcome of Pinoteau's method for the three products used in this study. The figures show calculated resistances using Pinoteau's method (Resistance Integration) at 15, 30, 60, 90 and 120 minutes in addition to the times where pull-out failure in fire tests occurred.

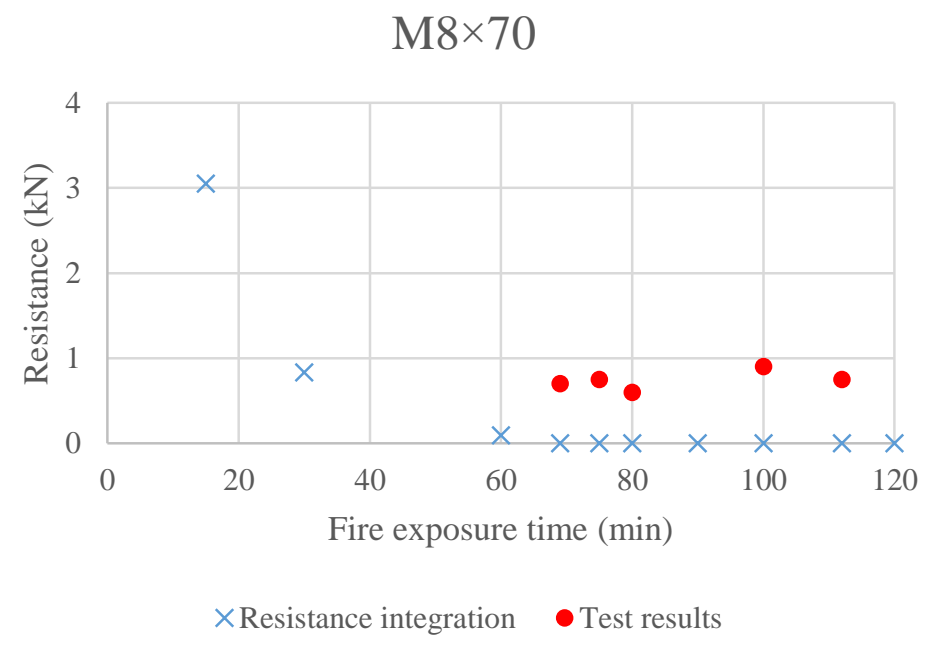

Fig. 3. Fire resistance of $M 8 \times 70$ bonded anchor

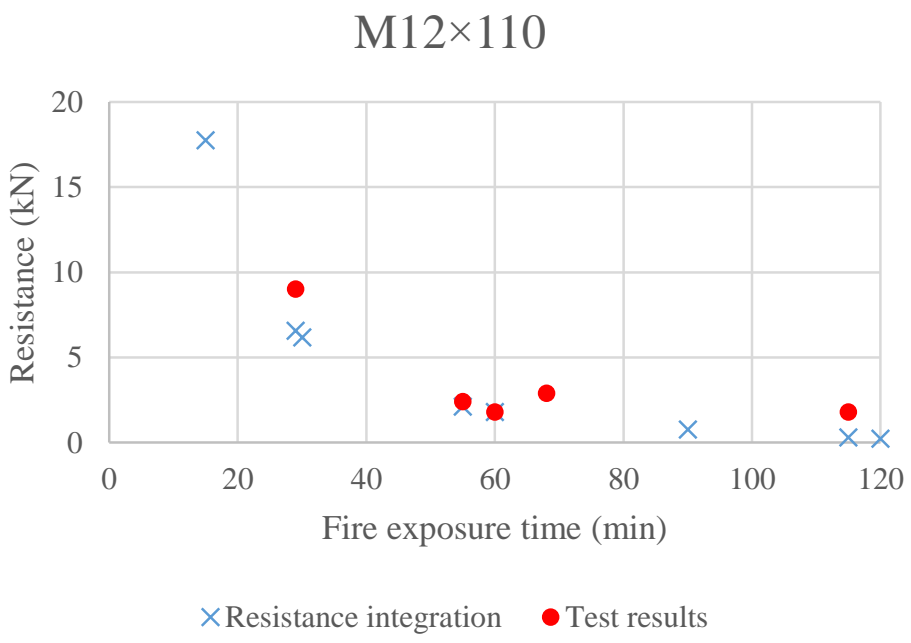

Fig. 4. Fire resistance of $\mathrm{M} 12 \times 110$ bonded anchor

From the previous results it can be concluded that Pinoteau's method (Resistance Integration) can be used for the design of bonded anchors under fire. Indeed, the method yields conservative design values compared to fire tests. However, some calculated resistances are too conservative where the design method shows that the anchor possesses no resistance under fire. This is due to the fact that Resistance Integration is based on the bond stress vs. temperature curve. So far, this curve was only assessed through the approach in EAD 330087 up to a maximum temperature $\mathrm{T}_{\max }$ (around $300^{\circ} \mathrm{C}$ ) for a maximum test duration of less than 3 hours, beyond of which no extrapolation is allowed. Therefore, in the Resistance Integration process, when the temperature of the anchor (in a segment or over the whole embedment depth) exceeds the maximum temperature of the bond stress vs. temperature curve, the segment is attributed zero bond stress hence no resistance. It should be noted that for an anchor exposed directly to fire, temperature profiles reach and exceed $300^{\circ} \mathrm{C}$ along the embedment depth very rapidly. This explains the difference between calculated 
resistances and fire test results since in reality the anchor still holds a certain resistance at high temperatures $\mathrm{T}_{\max }$ (mostly by friction).

In order to minimize the difference between calculated resistances (Pinoteau's method) and fire test results, a parametric study was conducted to assess the influence of considering the remaining bond stress beyond $\mathrm{T}_{\max }$ in the Resistance Integration Method. This study is only informative and is not based on data points beyond $\mathrm{T}_{\max }$, therefore for the design of anchors in reality, this extension of the bond stress vs. temperature curve should be based on test data. A parametric study was conducted and it was deduced that extending the bond stress vs. temperature curve up to $450^{\circ} \mathrm{C}$ was beneficial for the design values of the studied adhesives.

Figure 5 show the beneficial influence of considering the bond stress beyond $\mathrm{T}_{\max }$ in the design method, on the calculated design values (fire resistance of the anchor).

It should be noted that Pinoteau's method does not count as a predictive method for the fire resistance of bonded anchors. It contains several safety factors:

1. The method is based on evaluation of PIRs according to [10]. The resulting bond stress vs. temperature curve is slightly conservative compared to tests on bonded anchors (threaded rod inserts). Indeed, adopting a curve based on tests with rods could have a beneficial impact on the calculated design values.

2. The bond stress vs. temperature curve is obtained for a constant load and increased temperature applied on the anchor until failure. Failure temperature is obtained by the weighted average of measurements of two thermocouples (head and bottom of the anchor) $=1 / 3$ of the higher measured temperature and $2 / 3$ of the lower measured temperature, yielding a conservative failure temperature value.

3. The bond stress vs. temperature curve is stopped at an upper limit for PIRs of approximately $300^{\circ} \mathrm{C}$. This limit should be reevaluated for bonded anchors since their temperature increases rapidly over short periods of time in fire situations. The conversion of temperature profiles to stress (resistance) profiles based on this curve is therefor cut beyond this maximum temperature (zero resistance) because the behavior of the anchor is unknown for higher temperatures.

4. The stress (resistance) profiles are obtained based on temperature profiles calculated according to Eurocode thermophysical properties of concrete and steel using numerical modelling. These material properties are design properties. Calculation based on these properties yield conservative design values and not physically representative values.

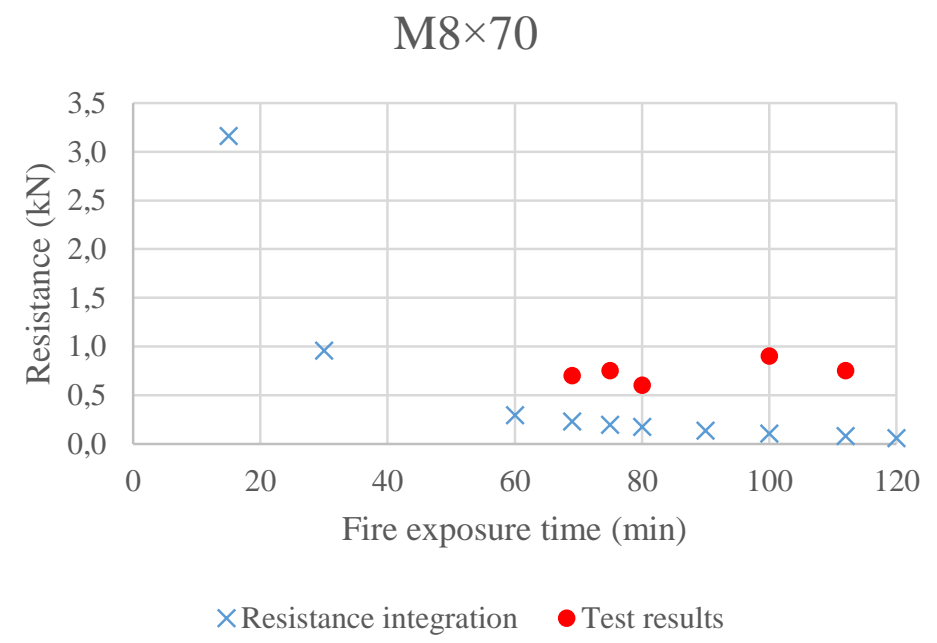

Figure 5. Fire resistance of $\mathrm{M} 8 \times 70$ bonded anchor using Adhesive- 3 after consideration of bond stress beyond $\mathrm{T}_{\max }$ 


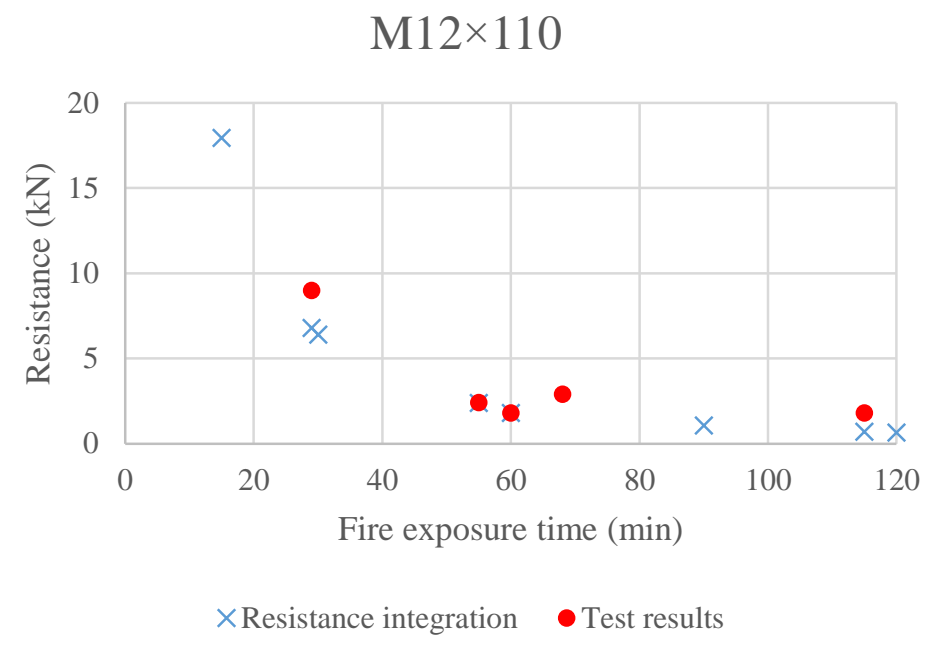

Figure 6. Fire resistance of M12×110 bonded anchor using Adhesive-3 after consideration of bond stress beyond $\mathrm{T}_{\max }$

A summary of the results of fire tests and calculated design values from both campaigns is shown in Table 1.

Table 1. Summary of results of pull-out fire tests on bonded anchors

\begin{tabular}{|c|c|c|c|c|}
\hline $\begin{array}{c}\text { Anchor geometry } \\
\text { size } \times \text { embedment [mm] }\end{array}$ & $\begin{array}{c}\text { Applied } \\
\text { load [kN] }\end{array}$ & $\begin{array}{c}\text { Pull-out failure } \\
\text { time under fire } \\
{[\mathrm{min}]}\end{array}$ & $\begin{array}{c}\text { Calculated fire resistance } \\
\text { at failure time } \\
{[\mathrm{kN}]}\end{array}$ & $\begin{array}{c}\text { Calculated fire resistance at failure time } \\
\text { after consideration of bond stress- } \\
\text { temperature curve beyond } \mathrm{T}_{\text {max }} \\
{[\mathrm{kN}]}\end{array}$ \\
\hline \multirow{5}{*}{$\mathrm{M} 8 \times 70$} & 0.75 & 112 & 0 & 0.08 \\
\cline { 2 - 5 } & 0.90 & 100 & 0 & 0.11 \\
\cline { 2 - 5 } & 0.60 & 80 & 0 & 0.17 \\
\cline { 2 - 5 } & 0.75 & 75 & 0 & 0.20 \\
\cline { 2 - 5 } & 0.70 & 69 & 0 & 0.23 \\
\hline \multirow{5}{*}{$\mathrm{M} 12 \times 110$} & 1.80 & 115 & 0.31 & 0.69 \\
\cline { 2 - 5 } & 1.80 & 60 & 1.80 & 1.80 \\
\cline { 2 - 5 } & 2.40 & 55 & 2.12 & 2.40 \\
\cline { 2 - 5 } & 2.90 & 68 & & 6.78 \\
\cline { 2 - 5 } & 9.0 & 29 & 6.57 & \\
\hline
\end{tabular}




\section{CONCLUSIONS}

This paper presents validation and parametric study of Pinoteau's method (Resistance Integration) for calculating the load-bearing capacity of bonded anchors in uncracked concrete under ISO 834-1 fire conditions [16]. The method employs 3D transient heat transfer equations to obtain temperature profiles along the embedment depth of anchors. The temperature profiles then serve as input for the bond Resistance Integration Method, in which bond strength contributions of discrete segments along the embedment depth of anchors is computed during fire exposure. In this study, the method was validated with experimental results obtained in a research project at CSTB on an epoxy based adhesive. The method yields conservative calculations of load-bearing capacities at various fire exposure times compared to experimental results for two common configurations and sizes of bonded anchors $(M 8 \times 70$ and M12×110).

A parametric study was also presented after experimental validation of the method. This study investigated the influence of considering the bond stress vs. temperature curve beyond the maximum temperature allowed for the assessment of Post-Installed Rebars in EAD 330087, resulting in the following conclusion:

- Extending the curve up to a temperature of $450^{\circ} \mathrm{C}$ yielded more advantageous and conservative design values (less conservative than stopping the curve at $\sim 300^{\circ} \mathrm{C}$ ) for bonded anchors under fire for the studied adhesives.

The authors recommend that the maximum temperature limit gets lifted for bonded anchors since anchors are directly exposed to fire and therefore reach much higher temperatures in a short period of time. The authors also recommend that the maximum bond stress limit of $10 \mathrm{MPa}$ imposed on PIRs gets lifted for bonded anchors. Indeed, this limit corresponds to the minimum bond strength required for the evaluation of PIRs compared to cast-in rebars. This criterion is not required for bonded anchors and therefore the reference value (upper limit) should be established at the value of bond strength at ambient temperature.

\section{ACKNOWLEDGMENT}

The experimental research presented in this paper was conducted at the fire-resistance laboratory at CSTB (Centre Scientifique et Technique du Bâtiment). The authors would like to acknowledge Dr. Mhd Amine Lahouar, Dr. Duc Toan Pham and Eng. Paul Lardet, Mr. Romuald Avenel, Mr. Stéphane Charuel, Mr. Luntala Diafunana, Mr. Jean-François Moller, Mr. Paulo Pangia Ngani, Mr. Wissem Lassadi and Mr. Florian Demoulin at CSTB for their contribution to this work. 


\section{REFERENCES}

1. Eligehausen R, Werner F. Recent developments and open problems in fastening technique. In: $2^{\text {nd }}$ international symposium on connections between steel and concrete, Stuttgart, FIB, Germany; 2007.

2. Petit J, Nassiet V, Baziard YH-RB. Etude de la durabilité des assemblages collés. Techniques de l'ingénieur; 2005. p. COR160.

3. Zhang Y, Lou G, Chen K, Li G. Residual strength of organic anchorage adhesive for post-installed rebar at elevated temperatures and after heating. Fire Technol J 2016;52:877-95.

4. Muciaccia, G., Navarrete, D.D., Pinoteau, N., Mege, R. Effects of different test apparati and heating procedures on the bond properties of post-installed rebar connections under elevated temperatures. Mater Struct (2019) 52: 47.

5. EOTA. EAD 330499-01-0601. Bonded fasteners for use in concrete. June 2019.

6. ICC-ES. AC308. Acceptance criteria for post-installed adhesive anchors in concrete elements. October 2017.

7. National Transportation Safety Board, 2006. Ceiling Collapse in the Interstate 90 Connector Tunnel Boston, Massachusetts.

8. Georgia Departement of Transportation, 2012. $17^{\text {th }}$ Street Bridge Canopy Failure Investigation, s.1.: WJE.

9. Reis J. Effect of temperature on the mechanical properties of polymer mortars. Mater Res 2012;15(4):6459.

10. EOTA. EAD 330087-00-0601. Systems for post-installed rebar connections with mortar. May 2018.

11. Eligehausen R, Mallée R, Silva JF. Anchorage in concrete construction. Ernst \& Sohn; 2006.

12. EN 1992-4. Eurocode 2 - Design of concrete structures - Part 4 : Design of fastenings for use in concrete. September 2018.

13. Reichert M, Thiele C. Qualification of bonded anchors in case of fire. Proceedings of the $3^{\text {rd }}$ international symposium on connections between steel and concrete. Stuttgart, Germany. September 2017. p. 1191-9.

14. Lakhani H, Hofmann J. A numerical method to evaluate the pull-out strength of bonded anchors under fire. Proceedings of the $3^{\text {rd }}$ international symposium on Connections between Steel and Concrete. Stuttgart, Germany. September 2017. p. 1179-90.

15. Pinoteau N [Ph.D thesis]: Behavior of post-installed rebars in concrete under fire, Lille: University of Lille (France). https://ori-nuxeo.univ-lille1.fr/nuxeo/site/esupversions/de94303f-5d72-4f61-9183-515ff08b490b; 2013.

16. ISO 834-1 International Standard. Fire-resistance tests - Elements of building construction - Part 1: General requirements. First edition, 15 September 1999.

17. Lahouar MA, Pinoteau N, Caron J-F, Forêt, Rivillon Ph. Fire design of post-installed rebars: full-scale validation test on a $2.94 \times 2 \times 0.15 \mathrm{~m} 3$ concrete slab subjected to ISO 834-1 fire. Eng Struct J 2018;174:8194.

18. Lahouar MA, Pinoteau N, Caron J-F, Forêt G, Mège R. A nonlinear shear-lag model applied to chemical anchors subjected to a temperature distribution. Int J Adhe Adhes 2018;84:438-50.

19. Reichert, M, Thiele, C, 2017. Verbunddübel im Brandfall-DIBt. Kaiserslautern, University of Kailserslautern.

20. Lakhani H, Hofmann J. On the pull-out capacity of post-installed bonded anchors and rebars during fire. Proceedings of the $10^{\text {th }}$ International Conference on Structures in Fire. Belfast, UK. June 2018. p. 165-71.

21. Al-Mansouri O, Mège R, Pinoteau N, Guillet T, Piccinin R, McBride K, Rémond S. Numerical investigation of parameters influencing fire evaluation tests of chemically bonded anchors in uncracked concrete. Eng Struct J 2020;209:110297.

22. Al-Mansouri O, Mege R, Pinoteau N, Guillet T, Rémond S. Influence of testing conditions on thermal distribution and resulting load-bearing capacity of bonded anchors under fire. Eng Struct J 2019;192:190204.

23. EN 1363-1. Fire resistance tests Part 1: General requirements. February 2020.

24. EN 1993-1-2. Eurocode 3: Design of steel structures - Part 1-2: General rules - Structural fire design. November 2005. 
25. EN 1992-1-2. Eurocode 2: Design of concrete structures - Part 1-2: General rules - Structural fire design. July 2008.

26. ACI 318-14, "Building code requirements for reinforced concrete" Detroit, Michigan: American Concrete Institute, 2014.

27. EOTA TR 020. Evaluation of anchorages in concrete concerning resistance to fire. European Organization for Technical Approvals Technical report no. 20. May 2005. 